\title{
Excellent Clinical Outcomes and Rates of Return to Play After Arthroscopic Rotator Cuff Repair for Traumatic Tears in Athletes Aged 30 Years or Less
}

\author{
Martin S. Davey, M.B., B.Ch., M.Ch., M.R.C.S., Eoghan T. Hurley, M.B., B.Ch., M.Ch., \\ John P. Scanlon, M.B., B.Ch., Mohamed Gaafar, F.R.C.S.(TrGOrth), \\ Leo Pauzenberger, M.D., and Hannan Mullett, M.Ch., F.R.C.S.(TrGOrth)
}

\begin{abstract}
Purpose: To evaluate clinical outcomes and rate of return to play (RTP) among athletes aged 30 years or younger who have undergone an arthroscopic rotator cuff repair (ARCR) after trauma. Methods: We performed a retrospective review of patients who underwent an ARCR with a minimum of 12 months' follow-up between 2012 and 2019. Patients were followed up to assess the American Shoulder and Elbow Surgeons score, Subjective Shoulder Value, visual analog scale score, and satisfaction level. Whether patients were able to RTP was reported, in addition to the timing of return and the level to which they returned. Results: Our study included 20 athletes (20 shoulders), with a mean follow-up period of 31.8 months. All patients were satisfied with their surgical procedure, and all would opt to undergo surgery again. Overall, $85 \%$ returned to sport and $50.0 \%$ returned to the same level or a higher level. The overall mean American Shoulder and Elbow Surgeons score was 92.4; mean Subjective Shoulder Value, 87.0; and mean visual analog scale score, 0.7. At final follow-up, only 1 patient $(5.0 \%)$ had undergone a revision procedure. Of the 15 patients who played collision sports, 93.3\% returned to sport but only $60.0 \%$ returned to the same level or a higher level. Conclusions: After ARCR, athletes aged 30 years or younger show excellent functional outcomes with high rates of patient satisfaction and RTP after the procedure. Level of Evidence: Level IV, therapeutic case series.
\end{abstract}

$\mathbf{R}$ otator cuff tears (RCTs) are a common pathology occurring mostly in older patients, with the prevalence approaching $65 \%$ in those aged 80 years or older in the general population. ${ }^{1}$ However, RCTs may occur in young athletes due to trauma causing shoulder pain, weakness, and functional deficits resulting in time away from sport. ${ }^{2}$ Although many RCTs can be managed conservatively initially, those that do not

From Sports Surgery Clinic, Dublin, Ireland (M.S.D., E.T.H., J.P.S., M.G., L.P., H.M.); Royal College of Surgeons in Ireland, Dublin, Ireland (M.S.D., E.T.H.); and National University of Ireland, Galway, Galway, Ireland (E.T.H.).

The authors report no conflicts of interest in the authorship and publication of this article. Full ICMJE author disclosure forms are available for this article online, as supplementary material.

Received May 19, 2020; accepted January 12, 2021.

Address correspondence to Eoghan T. Hurley, M.B., B.Ch., M.Ch., Sports Surgery Clinic, Santry, Dublin, Ireland.E-mail: eoghanhurley@rcsi.ie

(C) 2021 THE AUTHORS. Published by Elsevier Inc. on behalf of the Arthroscopy Association of North America. This is an open access article under the CC BY-NC-ND license (http://creativecommons.org/licenses/by-nc-nd/4.0/). 2666-061X/20891

https://doi.org/10.1016/j.asmr.2021.01.003 respond may undergo arthroscopic rotator cuff repair (ARCR).

Despite athletes accounting for a minority of patients undergoing ARCR procedures, there has been a steady increase in the number of athletes undergoing ARCR for traumatic RCTs over the past 2 decades. ${ }^{3,4}$ Competitive athletes, particularly those taking part in high levels of overhead-throwing or collision sports, are increasingly likely to have RCTs, which may often require ARCR., Although an increasing number of young athletes are requiring ARCR, most evidence on functional outcomes remains based on the more elderly patient at 2 years' follow-up after ARCR..$^{7-9}$ Despite there being limited evidence to support the return of competitive athletes to preinjury levels of function and play, ${ }^{10}$ few studies have reported on the clinical outcomes in the young athlete hoping to return to play (RTP) after ARCR. ${ }^{11-22}$

The purpose of this study was to evaluate clinical outcomes and rate of RTP among athletes aged 30 years or younger who have undergone an ARCR after trauma. Our hypothesis was that young athletes undergoing ARCR would show satisfactory clinical outcomes and levels of RTP at final follow-up. 


\section{Methods}

\section{Inclusion Criteria}

We carried out a retrospective review of all patients who underwent ARCR performed by a single surgeon (H.M.) between July 2012 and March 2019. The inclusion criteria for this study included athletes presenting acutely after trauma while playing organized sports, age 30 years or younger, ARCR performed within 3 months of injury, and a minimum of 12 months' follow-up. The exclusion criteria included previous ipsilateral shoulder surgery and concomitant repair of other pathology after diagnostic arthroscopy.

\section{Surgical Technique and Rehabilitation Protocol}

Rotator cuff repairs were performed as necessary with 1 or more suture anchors in a single- or doublerow configuration. In case of a double-row repair, a configuration with medial knots and knotless lateral anchors was used. Because all patients included in this series were young and active, a double-row repair with medial knots and knotless lateral anchors was performed in all cases. A mixture of knotted medial-row anchors with No. 2 high-strength sutures (TwinFix [Smith \& Nephew, Andover, MA] and Y-Knot [ConMed, Utica, NY]) and knotless lateral-row anchors (SwiveLock [Arthrex, Naples, FL] and Healicoil [Smith \& Nephew]) was used. Depending on the extent of the tear, 1 or 2 medial-row anchors and 1 or 2 lateral anchors were used in this series. In patients with concomitant subscapularis tears, an additional suture anchor was used.

The rehabilitation protocol was the same for all patients. Postoperatively, the shoulder was placed in a sling for 3 weeks, but passive exercises and non-resisted activities of daily living, without excessive elevation or external rotation of the shoulder, were allowed. Patients started active physiotherapy in the fourth postoperative week, which continually increased in intensity over the next 9 weeks. A controlled return to contact in training was allowed after 12 weeks if comfortable, whereas a return to full contact and competition usually followed within the next 3 months.

\section{Clinical Outcomes}

An evaluation of postoperative patient-reported outcomes was performed after a telephone survey including the American Shoulder and Elbow Surgeons (ASES) score, Subjective Shoulder Value (SSV), visual analog score (VAS) score, rate of RTP, level of RTP, patient satisfaction, willingness to undergo the same procedure again, postoperative complications, and further operations on the ipsilateral shoulder. Collision sports were defined as rugby, Gaelic athletic games, hockey, and football in the National Football League. Additionally, RTP was defined as a return to organized sports involving competition in league format and was self-reported by the athletes at final follow-up.

\section{Statistical Analysis}

Statistical analysis was carried out using IBM SPSS Statistics for Windows software (version 22.0 [2013 release]; IBM, Armonk, NY).

\section{Results}

\section{Patient Demographic Characteristics}

Overall, 996 patients underwent ARCR. After analysis, 20 patients (16 male and 4 female patients), including 20 shoulders, met the inclusion criteria. The patients comprised 2 professional athletes $(10.0 \%), 16$ competitive athletes $(80.0 \%)$ and 2 recreational athletes $(10.0 \%)$; there were 15 collision athletes $(75.0 \%)$. Overall, the mean age of included patients was $25.5 \pm$ 3.5 years (range, 18-29 years), with a mean follow-up period of $31.8 \pm 14.7$ months (range, 15-56 months). All included athletes underwent ARCR for supraspinatus tears, with 2 patients undergoing concomitant subscapularis tear repair. A summary of patient demographic characteristics is presented in Table 1.

\section{Patient-Reported Outcomes}

At final follow-up, the mean ASES score was $92.4 \pm 5.4$ (range, 83.3-100); mean SSV, $87.0 \pm 10.2$ (range, 70100); and mean VAS score, $0.7 \pm 1.0$ (range, 0.0-3.0). Overall, $100 \%$ of patients were satisfied at final follow-up, and all included patients reported that they would opt to undergo ARCR surgery again. A summary of patientreported outcomes is presented in Table 2.

\section{Return to Play}

At final follow-up, the overall rate of RTP was $85.0 \%$, with a mean duration of $5.8 \pm 2.8$ months required after ARCR to RTP. Overall, $50.0 \%$ of athletes returned to the same level or a higher level of sport and 30.0\% returned to a lower level of sport. After ARCR, 1 patient $(5.0 \%)$ opted to change sport. For the professional and competitive athletes, the overall rate of RTP was $88.9 \%$. Among the 3 patients who did not RTP $(15.0 \%)$, they reported this was because of the shoulder injury in $10 \%$ of cases and because of other factors in $5.0 \%$. A summary of RTP is presented in Table 3.

\section{Complications}

Overall, no intraoperative complications $(0 \%)$ were reported for any of the ARCR procedures. Only 1 subsequent procedure $(5.0 \%)$ was reported after ARCR: a single arthroscopic stabilization in a collision athlete.

\section{Collision Athletes}

Overall, 15 collision athletes ( 13 male and 2 female patients) who underwent ARCR were included in this study, with a mean age of $25.1 \pm 3.3$ years (range, $18-29$ 
Table 1. Patient Characteristics

\begin{tabular}{lllcc}
\hline \multicolumn{1}{c}{ Outcome } & $\mathrm{n}$ & $\%$ & Mean & Range \\
\hline Shoulders & 20 & - & - & - \\
Patients & 20 & - & - & - \\
Male patients & 16 & 80 & - & - \\
Age, yr & - & - & 25.5 & $18-29$ \\
Follow-up, mo & - & - & 31.8 & $15-56$ \\
Collision athlete & 15 & 75 & - & - \\
Overhead sport athlete & 4 & 20 & - & - \\
Professional athlete & 2 & 10 & - & - \\
Competitive athlete & 16 & 80 & - & - \\
Recreational athlete & 2 & 10 & - & - \\
\hline
\end{tabular}

years) and mean follow-up period of $31.1 \pm 12.9$ months (range, 15-56 months). At final follow-up, the mean ASES score was 94.4 \pm 4.6 (range, 86.7-100); mean SSV, $87.0 \pm 10.2$ (range, 75-100); and mean VAS score at rest, $0.5 \pm 0.9$ (range, $0-2$ ). The overall rate of RTP was $93.3 \%$, with a mean duration of $5.9 \pm 3.0$ months required after ARCR to RTP. Overall, $60.0 \%$ of collision athletes returned to the same level or a higher level of sport and $33.3 \%$ returned to a lower level of sport $(20 \%$ because of shoulder issues). No intraoperative complications $(0 \%)$ were reported, and only 1 subsequent procedure $(5.0 \%)$ was reported after ARCR: a single arthroscopic stabilization in a collision athlete. All patients reported being satisfied with the ARCR procedure at final follow-up. A summary of findings specific to collision athletes is presented in Table 4.

\section{Discussion}

The most important finding from this study was that patients aged 30 years or younger undergoing ARCR reported excellent clinical outcomes and satisfactory levels of return to sport at short-term follow-up. Both collision and non-collision athletes were satisfied with their pain levels and functional outcomes after ARCR while reporting high rates of RTP. Thus, ARCR is a reasonable option in athletes who have traumatic RCTs and are hoping to RTP; however, counseling is required because many young athletes are unable to RTP at their preinjury level after ARCR.

Shoulder injuries are more common among athletes when compared with the general population; however,

Table 2. Patient-Reported Outcomes

\begin{tabular}{lcccc}
\hline \multicolumn{1}{c}{ Outcome } & $\mathrm{n}$ & $\%$ & Mean & Range \\
\hline Total & 20 & 100 & - & - \\
Satisfied & 20 & 100 & - & - \\
Patient would undergo surgery again & 20 & 100 & - & - \\
ASES score & - & - & 92.4 & $83.3-100$ \\
SSV & - & - & 87.0 & $70-100$ \\
VAS score & - & - & 0.7 & $0-3$ \\
Revision surgery & 1 & 5.0 & - & - \\
\hline ASES, American Shoulder and Elbow Surgeons; & SSV, Subjective \\
Shoulder Value; VAS, visual analog scale. & & &
\end{tabular}

Table 3. Return to Play

\begin{tabular}{llll}
\hline \multicolumn{1}{c}{ Outcome } & $\mathrm{n}$ & $\%$ & Mean \\
\hline RTP & 17 & 85 & \\
Time to RTP, mo & - & - & 5.8 \\
RTP at SL or HL & 10 & 50 & \\
RTP at LL & 6 & 30 & \\
RTP at LL owing to shoulder-related factor & 4 & 20 & \\
RTP at LL owing to other factor & 2 & 10 & \\
Changed sport & 1 & 5 & \\
No RTP & 3 & 15 & \\
No RTP owing to shoulder-related factor & 2 & 10 & \\
No RTP owing to other factor & 1 & 5 &
\end{tabular}

HL, higher level; LL, lower level; RTP, return to play; SL, same level.

the incidence of RCTs has been shown to increase proportionally with increasing age. ${ }^{18}$ Although previously believed to be uncommon in those aged younger than 40 years, there is growing evidence showing that higher numbers of RCTs occur in the young athlete. ${ }^{23,24}$ Multiple cadaveric and clinical studies have reported rates of RCTs varying from $0 \%$ to $20 \% \cdot{ }^{25-28}$ However, the incidence of RCTs is believed to be underdiagnosed in the young athletic patient, particularly athletes who play overhead-throwing or collision sports. $^{19,29-31}$ Although commonly asymptomatic, multiple studies in recent years have found that between $40 \%$ and $95 \%$ of young overhead-throwing athletes, as well as between $35 \%$ and $100 \%$ of young collision athletes, may have evidence of small traumatic RCTs. ${ }^{30,32}$ Although many of these young patients with RCTs may initially be treated with conservative management, they often require subsequent ARCR. ${ }^{22,33,34}$

In young athletes undergoing ARCR, discussion of athlete-specific outcomes is required when counseling

Table 4. Findings Specific to Collision Athletes

\begin{tabular}{lcccc}
\hline \multicolumn{1}{c}{ Outcome } & $\mathrm{n}$ & $\%$ & Mean & Range \\
\hline Shoulders & 15 & - & - & - \\
Male patients & 13 & 86.7 & - & - \\
Professional & 2 & 13.3 & - & - \\
Competitive & 13 & 86.7 & - & - \\
Age, yr & - & - & 25.1 & $18-29$ \\
Follow-up, mo & - & - & 31.1 & $15-56$ \\
ASES score & - & - & 94.4 & $86.7-100$ \\
SSV & - & - & 87.0 & $75-100$ \\
VAS score & - & - & 0.5 & $0-2$ \\
RTP & 14 & 93.3 & - & - \\
Time to RTS, mo & - & - & 5.9 & $3-12$ \\
RTP at SL or HL & 9 & 60.0 & - & - \\
RTP at LL & 5 & 33.3 & - & - \\
RTP at LL owing to shoulder-related & 3 & 20.0 & - & - \\
$\quad$ factor & & & & \\
No RTP & 1 & 6.7 & - & - \\
No RTP owing to other factor & 1 & 6.7 & - & - \\
\hline
\end{tabular}

ASES, American Shoulder and Elbow Surgeons; HL, higher level; LL, lower level; RTP, return to play; SL, same level; SSV, Subjective Shoulder Value; VAS, visual analog scale. 
them prior to ARCR. Specific sport-related factors such as overall RTP, level of RTP, and timing of RTP are important elements warranting discussion when opting for surgical management of RCTs in the athlete. ${ }^{22} \mathrm{~A}$ systematic review by Klouche et al. ${ }^{35}$ reported that the overall RTP rate after ARCR was nearly $85 \%$. However, subsequent subgroup analysis by sport showed that the results were skewed because high rates of RTP were reported in mostly noncontact sports such as baseball, tennis, and golf, which accounted for nearly $60 \%$ of included patients. Similarly, a recent study by Rossi et al. ${ }^{36}$ found that nearly $90 \%$ of athletes managed to successfully RTP at less than 6 months after ARCR, with significantly improved patient-reported pain and functional scores; however, no subgroup analysis was performed between sports. Additionally, nearly $80 \%$ of young athletes managed to RTP in a systematic review published by Reuter et al., ${ }^{37}$ but the mean time to RTP was more than 8 months. Similarly, the overall rates of RTP in our series are in line with the literature, given that $85 \%$ of our young athletes were able to RTP, with satisfactory pain and function scores after ARCR.

Although most studies have reported high levels of overall RTP after ARCR, the level of RTP for the young competitive athlete is still an area of concern. Whereas Dines et al. ${ }^{38}$ reported their finding that over $80 \%$ of young competitive baseball players returned to professional sport after ARCR, most of the evidence is contradictory of this finding. Recent studies by both Altintas et al. ${ }^{39}$ and Millett et al. ${ }^{9}$ found that despite nearly threequarters of athletes successfully being able to RTP after their ARCR procedure, approximately $60 \%$ of competitive athletes managed to do so at their desired level. Additionally, Young et al. ${ }^{40}$ reported that although nearly $90 \%$ of the professional tennis players in their series managed to RTP, only $25 \%$ did so at their preinjury level. Although this study found that nearly $90 \%$ of the professional and competitive athletes and over $85 \%$ of all included athletes managed to successfully RTP, only half of all included athletes were able to RTP at the same level as their preinjury status or at a higher level.

Our study reported on a variety of athletes, with threequarters of included athletes being involved in collision sports and one-fifth, in overhead-throwing sports. Multiple studies have described the challenge for the overhead athlete in achieving RTP after ARCR, with a wide range of rates of RTP from less than $20 \%$ to nearly $90 \%$ reported for these athletes. ${ }^{37,41-45}$ However, despite collision athletes having high frequencies of shoulder pathologies including not only glenohumeral instability but also traumatic RCTs, RTP in the young collision athlete after ARCR remains a lesser-discussed topic. $^{30,32,46,47}$ Tambe et al. ${ }^{10}$ reported in their series of collision athletes that approximately $90 \%$ managed to RTP at 5 months after ARCR, despite nearly half of the players showing findings of anterior shoulder instability.
Similarly, Goldberg et al. ${ }^{48}$ found that nearly $85 \%$ of the professional collision athletes in their series were able to RTP after ARCR, at a mean time of 9 months postoperatively. Our study had similar findings, given that over $90 \%$ of the collision athletes in our cohort managed to RTP, but in contrast, this occurred at a mean of just under 6 months after ARCR. However, over one-third did not RTP at their preinjury level of sport.

The literature reports a wide range of revision rates after ARCR, with between $0 \%$ and $55 \%$ of cases reported to require revision after ARCR. ${ }^{36,49-53}$ Although most of such studies in the literature report revision rates for older, nonathletic patients, discrepancies still exist for revision rates after ARCR in the young athletic patient. In their systematic review, Klouche et al. ${ }^{35}$ reported a revision rate of less than $8 \%$ in athletes. Similarly, Azzam et al. ${ }^{5}$ found that nearly $8 \%$ of the young athletes in their study required a revision. In contrast, Rossi et al. $^{36}$ found that no revisions were required in their 72-patient series; however, there were 5 cases of adhesive capsulitis at a mean of 54 months' follow-up. A systematic review by Millett et al. ${ }^{9}$ found that fewer than $2 \%$ of patients required revision surgery after ARCR; however, analysis was limited by heterogeneity. Although our study had a 5\% revision rate at a mean of nearly 3 years' follow-up, excellent rates of patient-reported satisfaction were found, given that $100 \%$ of the patients included in this study were satisfied with their ARCR.

\section{Limitations}

Our study has several limitations. Because this is a retrospective study, it possesses the limitations inherent to all retrospective reviews. Although rotator cuff injuries are still uncommon in our patient population, our small sample size limits analysis. Furthermore, the lack of preoperative patient-reported outcome measures limits further assessment in the validation of the postoperative results of this study because we could not correlate outcome scores.

\section{Conclusions}

After ARCR, athletes aged 30 years or younger show excellent functional outcomes with high rates of patient satisfaction and RTP after the procedure.

\section{References}

1. Teunis T, Lubberts B, Reilly BT, Ring D. A systematic review and pooled analysis of the prevalence of rotator cuff disease with increasing age. J Shoulder Elbow Surg 2014;23:1913-1921.

2. Virk MS, Levy DM, Kuhns BD, et al. Patient preference before and after arthroscopic rotator cuff repair: Which is more important, pain relief or strength return? Am J Orthop (Belle Mead NJ) 2017;46:E244-E250.

3. Bayle X, Pham TT, Faruch M, Gobet A, Mansat P, Bonnevialle N. No difference in outcome for open versus 
arthroscopic rotator cuff repair: A prospective comparative trial. Arch Orthop Trauma Surg 2017;137:1707-1712.

4. Acevedo DC, Paxton ES, Williams GR, Abboud JA. A survey of expert opinion regarding rotator cuff repair. J Bone Joint Surg Am 2014;96:e123.

5. Azzam MG, Dugas JR, Andrews JR, Goldstein SR, Emblom BA, Cain EL Jr. Rotator cuff repair in adolescent athletes. Am J Sports Med 2018;46:1084-1090.

6. Rahu M, Kartus JT, Põldoja E, Pedak K, Kolts I, Kask K. Do articular-sided partial-thickness rotator cuff tears after a first-time traumatic anterior shoulder dislocation in young athletes influence the outcome of surgical stabilization? Orthop J Sports Med 2018;6:2325967118781311.

7. Gurnani N, van Deurzen DFP, van den Bekerom MPJ. Shoulder-specific outcomes 1 year after nontraumatic fullthickness rotator cuff repair: A systematic literature review and meta-analysis. Shoulder Elbow 2017;9:247-257.

8. Katthagen JC, Bucci G, Moatshe G, Tahal DS, Millett PJ. Improved outcomes with arthroscopic repair of partialthickness rotator cuff tears: A systematic review. Knee Surg Sports Traumatol Arthrosc 2018;26:113-124.

9. Millett PJ, Espinoza C, Horan MP, et al. Predictors of outcomes after arthroscopic transosseous equivalent rotator cuff repair in 155 cases: A propensity score weighted analysis of knotted and knotless self-reinforcing repair techniques at a minimum of 2 years. Arch Orthop Trauma Surg 2017;137:1399-1408.

10. Tambe A, Badge R, Funk L. Arthroscopic rotator cuff repair in elite rugby players. Int J Shoulder Surg 2009;3:8-12.

11. Alley MC, Banerjee S, Papaliodis D, Tsitos K, Zanaros GS. Transosseous physeal-sparing rotator cuff repair in an adolescent football player. Orthopedics 2016;39:e353-e358.

12. Battaglia TC, Barr MA, Diduch DR. Rotator cuff tear in a 13-year-old baseball player: A case report. Am J Sports Med 2003;31:779-782.

13. Burns TC, Reineck JR, Krishnan SG. Rotator cuff tears in adolescent female catchers. J Shoulder Elbow Surg 2009;18: el3-el6.

14. Paschal SO, Hutton KS, Weatherall PT. Isolated avulsion fracture of the lesser tuberosity of the humerus in adolescents. A report of two cases. J Bone Joint Surg Am 1995;77:1427-1430.

15. Provance AJ, Polousky JD. Isolated avulsion fracture of the subscapularis tendon with medial dislocation and tear of biceps tendon in a skeletally immature athlete: A case report. Curr Opin Pediatr 2010;22:366-368.

16. Sikka RS, Neault M, Guanche CA. An avulsion of the subscapularis in a skeletally immature patient. Am J Sports Med 2004;32:246-249.

17. Turman KA, Anderson MW, Miller MD. Massive rotator cuff tear in an adolescent athlete: A case report. Sports Health $2010 ; 2: 51-55$.

18. Eisner EA, Roocroft JH, Moor MA, Edmonds EW. Partial rotator cuff tears in adolescents: Factors affecting outcomes. J Pediatr Orthop 2013;33:2-7.

19. Tarkin IS, Morganti CM, Zillmer DA, McFarland EG, Giangarra CE. Rotator cuff tears in adolescent athletes. Am J Sports Med 2005;33:596-601.

20. Vavken P, Bae DS, Waters PM, Flutie B, Kramer DE. Treating subscapularis and lesser tuberosity avulsion injuries in skeletally immature patients: A systematic review. Arthroscopy 2016;32:919-928.

21. Vezeridis PS, Bae DS, Kocher MS, Kramer DE, Yen YM, Waters PM. Surgical treatment for avulsion injuries of the humeral lesser tuberosity apophysis in adolescents. J Bone Joint Surg Am 2011;93:1882-1888.

22. Weiss JM, Arkader A, Wells LM, Ganley TJ. Rotator cuff injuries in adolescent athletes. J Pediatr Orthop B 2013;22: 133-137.

23. Hawkins RJ, Morin WD, Bonutti PM. Surgical treatment of full-thickness rotator cuff tears in patients 40 years of age or younger. J Shoulder Elbow Surg 1999;8:259-265.

24. Lazarides AL, Alentorn-Geli E, Choi JH, et al. Rotator cuff tears in young patients: A different disease than rotator cuff tears in elderly patients. J Shoulder Elbow Surg 2015;24:1834-1843.

25. Depalma AF. Accurate diagnosis in lesions of the shoulder and knee joint. Surg Clin North Am 1952:1761-1776.

26. Norwood LA, Barrack R, Jacobson KE. Clinical presentation of complete tears of the rotator cuff. J Bone Joint Surg Am 1989;71:499-505.

27. Wilson CL, Duff GL. Pathologic study of degeneration and rupture of the supraspinatus tendon. Arch Surg 1943;47: 121-135.

28. Zuckerman JD, Kummer FJ, Cuomo F, Simon J, Rosenblum S, Katz N. The influence of coracoacromial arch anatomy on rotator cuff tears. J Shoulder Elbow Surg 1992;1:4-14.

29. Lesniak BP, Baraga MG, Jose J, Smith MK, Cunningham S, Kaplan LD. Glenohumeral findings on magnetic resonance imaging correlate with innings pitched in asymptomatic pitchers. Am J Sports Med 2013;41:2022-2027.

30. Headey J, Brooks JH, Kemp SP. The epidemiology of shoulder injuries in English professional rugby union. Am J Sports Med 2007;35:1537-1543.

31. Shaffer B, Huttman D. Rotator cuff tears in the throwing athlete. Sports Med Arthrosc Rev 2014;22:101-109.

32. Foulk DA, Darmelio MP, Rettig AC, Misamore G. Fullthickness rotator-cuff tears in professional football players. Am J Orthop (Belle Mead NJ) 2002;31:622-624.

33. Kuhn JE. Current concepts: Rotator cuff pathology in athletes-A source of pain or adaptive pathology? Curr Sports Med Rep 2013;12:311-315.

34. Hurley ET, Maye AB, Mullett H. Arthroscopic rotator cuff repair: A systematic review of overlapping meta-analyses. JBJS Rev 2019;7:el.

35. Klouche S, Lefevre N, Herman S, Gerometta A, Bohu Y. Return to sport after rotator cuff tear repair: A systematic review and meta-analysis. Am J Sports Med 2016;44: $1877-1887$.

36. Rossi LA, Atala N, Bertona A, et al. Return to sports after in situ arthroscopic repair of partial rotator cuff tears. Arthroscopy 2019;35:32-37.

37. Reuter S, Imhoff AB, Martetschläger F. Impact of rotator cuff surgery on postoperative sporting activity. J Sports Med Phys Fitness 2018;58:480-488.

38. Dines JS, Jones K, Maher P, Altchek D. Arthroscopic management of full-thickness rotator cuff tears in Major League Baseball pitchers: The lateralized footprint repair technique. Am J Orthop (Belle Mead NJ) 2016;45:128-133. 
39. Altintas B, Anderson N, Dornan GJ, Boykin RE, Logan C, Millett PJ. Return to sport after arthroscopic rotator cuff repair: Is there a difference between the recreational and the competitive athlete? Am J Sports Med 2020;48: 252-261.

40. Young SW, Dakic J, Stroia K, Nguyen ML, Safran MR. Arthroscopic shoulder surgery in female professional tennis players: Ability and timing to return to play. Clin J Sport Med 2017;27:357-360.

41. Andrews JR, Broussard TS, Carson WG. Arthroscopy of the shoulder in the management of partial tears of the rotator cuff: A preliminary report. Arthroscopy 1985;1: $117-122$.

42. Riand N, Boulahia A, Walch G. Conflit postéro-supérieur de l'épaule chez le sportif: Résultats du débridement arthroscopique [Posterosuperior impingement of the shoulder in the athlete: Results of arthroscopic debridement in 75 patients]. Rev Chir Orthop Reparatrice Appar 2002;88:19-27 [in French].

43. Payne LZ, Altchek DW, Craig EV, Warren RF. Arthroscopic treatment of partial rotator cuff tears in young athletes. A preliminary report. Am J Sports Med 1997;25: 299-305.

44. Reynolds SB, Dugas JR, Cain EL, McMichael CS, Andrews JR. Débridement of small partial-thickness rotator cuff tears in elite overhead throwers. Clin Orthop Relat Res 2008;466:614-621.

45. Conway JE. Arthroscopic repair of partial-thickness rotator cuff tears and SLAP lesions in professional baseball players. Orthop Clin North Am 2001;32:443-456.
46. Porcellini G, Caranzano F, Campi F, Pellegrini A, Paladini P. Glenohumeral instability and rotator cuff tear. Sports Med Arthrosc Rev 2011;19:395-400.

47. Papalia R, Tecame A, Torre G, Narbona P, Maffulli N, Denaro V. Rugby and shoulder trauma: A systematic review. Transl Med UniSa 2015;12:5-13.

48. Goldberg JA, Chan KY, Best JP, Bruce WJ, Walsh W, Parry W. Surgical management of large rotator cuff tears combined with instability in elite rugby football players. Br J Sports Med 2003;37:179-181.

49. Yokoya S, Nakamura Y, Harada Y, Ochi M, Adachi N. Outcomes of arthroscopic rotator cuff repair with muscle advancement for massive rotator cuff tears. J Shoulder Elbow Surg 2019;28:445-452.

50. Kim KC, Shin HD, Cha SM, Kim JH. Repair integrity and functional outcomes for arthroscopic margin convergence of rotator cuff tears. J Bone Joint Surg Am 2013;95:536-541.

51. Thomazeau H, Boukobza E, Morcet N, Chaperon J, Langlais F. Prediction of rotator cuff repair results by magnetic resonance imaging. Clin Orthop Relat Res 1997: 275-283.

52. Harryman DT II, Mack LA, Wang KY, Jackins SE, Richardson ML, Matsen FA III. Repairs of the rotator cuff. Correlation of functional results with integrity of the cuff. J Bone Joint Surg Am 1991;73:982-989.

53. Tonotsuka H, Sugaya H, Takahashi N, Kawai N, Sugiyama H, Marumo K. Target range of motion at 3 months after arthroscopic rotator cuff repair and its effect on the final outcome. J Orthop Surg (Hong Kong) 2017;25: 2309499017730423. 